\title{
Bilateral acute angle closure glaucoma in a patient with dengue fever: case report
}

\author{
Glaucoma agudo bilateral em um paciente com dengue: relato de caso
}

\author{
Paulo de Tarso Ponte Pierre Filho ${ }^{1}$ \\ Jurandir Pontes Carvalho Filho ${ }^{2}$ \\ Érika Teles Linhares Pierre ${ }^{3}$
}

\begin{tabular}{|l|}
\hline ABSTRACT \\
\hline Ocular complications in dengue fever are uncommon but may result in \\
visual loss. The authors report the first documented case of a patient with \\
dengue fever who presented with simultaneous bilateral acute angle closure \\
glaucoma. The disease was confirmed by specific serological tests. Despite \\
the treatment, severe visual impairment occurred in this case.
\end{tabular}

Keywords: Dengue/complications; Glaucoma; Intraocular pressure/etiology; Brazil; Case reports [Publication type]

\section{INTRODUCTION}

Dengue fever (DF), the most important mosquito-borne viral disease affecting humans, occurs in over 100 countries, with an estimated 100 million cases per year and more than 2.5 billion people at risk worldwide ${ }^{(1)}$. It has emerged as a global public health problem in the past several decades and is now endemic in most tropical and subtropical areas of Central and South America, Southest Asia, the Western Pacific, Africa, and the Eastern Mediterranean $^{(1-2)}$.

Classic DF is a self-limiting, influenza-like illness caused by any of the four serotypes (DEN 1-4) of dengue virus. Dengue hemorrhagic fever (DHF) is a more severe form of the disease characterized by multisystem hemorrhagic manifestations, thrombocytopenia, increased vascular permeability, and plasma leakage. The early phase of DHF is indistinguishable from DF. The death rate for untreated DHF can be as high as $10-20 \%$ in places where emergency supportive treatment with intravenous fluids and platelet replacement is not readily accessible ${ }^{(3)}$.

In Brazil, more than a million cases were reported since the reintroduction of dengue in $1982^{(4)}$. The state of Ceará in the Northeast region of Brazil has had successive dengue epidemics that involved dengue virus serotypes DEN-1, DEN-2, and DEN-3. In 2006, there were 25,569 confirmed cases of dengue in this state and 172 fulfilled the World Health Organization criteria for $\mathrm{DHF}^{(5)}$. Usually, epidemics are more intense in cities, which is attributed to favorable epidemiological characteristics of rapidly growing urban agglomerations such as crowding, poor housing, as well as the existence of many putative breeding sites such as disposable containers, bottles and used tires ${ }^{(6)}$.

The principal vector of dengue infection is the hematophagous mosquito Aedes aegypti, a domestic-peridomestic insect. Man is the major vertebrate host and is the most important means of dispersion of the illness. To date, only this mosquito species has been associated with viral transmission in Brazil, despite the presence of Aedes albopictus, a competent vector in $\operatorname{Asia}^{(7)}$. 
Ophthalmic complications associated with DF and DHF have not been classically described. Within the ophthalmic community, this complication is being observed more frequently in recent times. However, only a few isolated case reports have been published ${ }^{(8-13)}$. We describe a patient with DF who developed bilateral acute angle closure glaucoma (AACG).

\section{CASE REPORT}

A previously healthy 67-year-old woman was admitted to the hospital with sudden loss of vision, intense ocular pain, lacrimation, photophobia, and redness of both eyes. She reported a 3-day history of fever, headache, nausea, and vomiting. Her previous medical and ocular history was unremarkable. Her physical examination revealed fever of $38^{\circ} \mathrm{C}$ and mild dehydration. No rash, jaundice or neck stiffness was noted. Blood test revealed a hemoglobin rate $12.9 \mathrm{~g} / \mathrm{dL}$, leukopenia (4.0 x 109/L), and thrombocytopenia (100 x 109/L). Alanine aminotransferase (ALT)/aspartate aminotransferase (AST) were 125/65 IU/L. Blood sugar, creatinine, electrolytes were normal.

In view of the severity of her visual symptoms she was referred to the Emergency Ophthalmology Department. Ophthalmological examination revealed that both eyes had visual acuity of hand motions, and elevated intraocular pressure (IOP) $(60 \mathrm{mmHg}$ in the right eye (RE) and $54 \mathrm{mmHg}$ in the left eye (LE)), by applanation. Both eyes were injected with corneal edema, shallow anterior chamber, iris atrophy, and fixed moderately dilated pupils (Figure 1). Both crystalline lenses exhibited nuclear sclerosis $2+$ and glaucomflecken, gonioscopy showed closed angles. No angle structures could be seen beyond Schwalbe's line, even on indentation, however, there were no goniosynechiae. Fundoscopy was not clear. The axial length was $22.13 \mathrm{~mm}$ and $22.12 \mathrm{~mm}$ in the RE and LE, respectively. B-Scan ultrasonography showed normal poste- rior segments in both eyes. A diagnosis of bilateral AACG was made and she was treated with $20 \%$ intravenous mannitol followed by topical $2 \%$ pilocarpine q.i.d., $0.5 \%$ timolol b.i.d., and $1 \%$ prednisolone acetate q.i.d. to both eyes. The IOP reduced to 22 and $20 \mathrm{mmHg}$ in right and left eyes respectively and bilateral laser iridotomies were performed.

On the following day her symptoms were present but improving. Computed tomography of the brain was normal. Blood tests showed a worsening leukopenia $\left(3 \times 10^{9} / \mathrm{L}\right)$ as well as thrombocytopenia $\left(80 \times 10^{9} / \mathrm{L}\right)$. During hospital stay, she also was given intravenous and oral fluids and paracetamol. Five days later she was almost asymptomatic with a platelet count of $108 \times 10^{9} / \mathrm{L}$ and was discharged. Specific serological tests (IgG and IgM) confirmed the dengue infection. She was advised to continue on timolol, pilocarpine and prednisolone eye drops for further 14 days. The patient's ocular findings improved gradually over the subsequent month. However, her visual symptoms had still not completely disappeared and visual acuity was 20/200 in both eyes. Her RE IOP was $20 \mathrm{mmHg}$ and left was $19 \mathrm{mmHg}$ without any treatment. The eye fundus exploration without dilatation did not exhibit significant alterations.

\section{DISCUSSION}

DF and DHF continue to be a global challenge. There is no specific treatment available nor any immediate prospect of a vaccine, and the mosquito control measures in most of the hyperendemic areas are inadequate ${ }^{(14)}$.

Ophthalmic complications in dengue infections are rare, but there has been an increasing number of cases reported in recent literature ${ }^{(8-14)}$. The main ocular findings include subconjunctival hemorrhages, macular edema and blot hemorrhages. Less common features include exudative retinal detachment, cotton wool spots, and anterior uveitis. A majority of patients were reported to have residual visual impairment ${ }^{(13-14)}$.
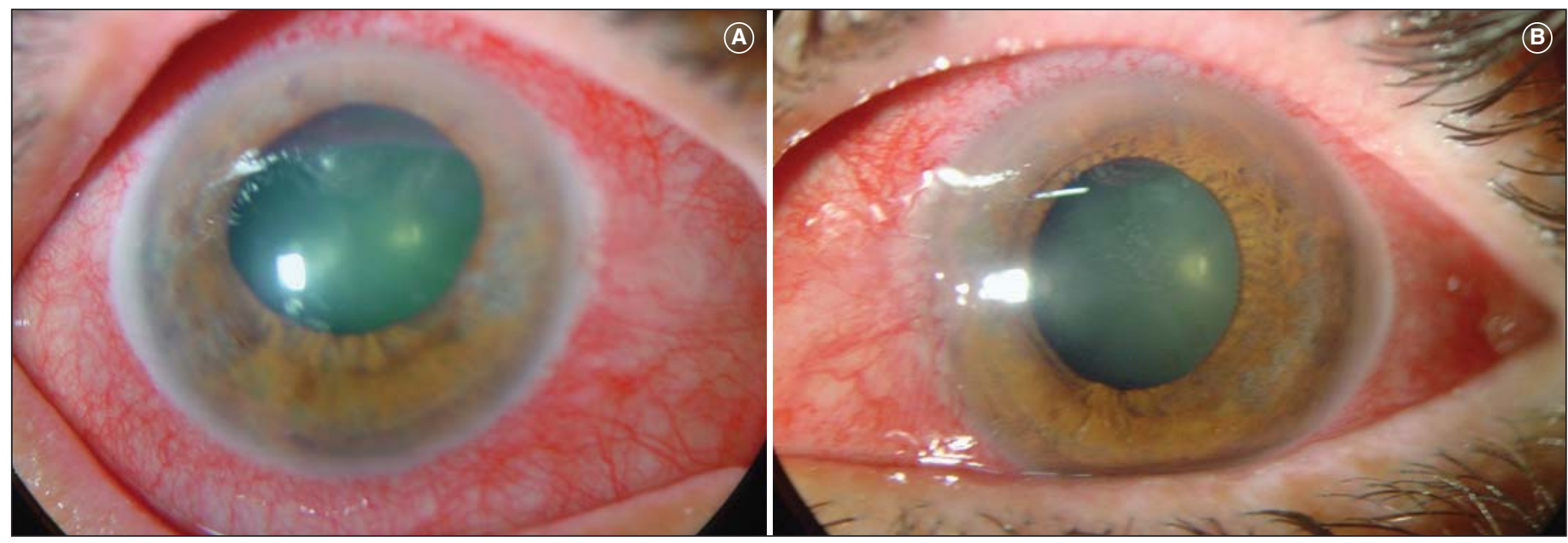

Figure 1 - Conjunctival hyperemia, corneal edema, iris atrophy, and fixed moderately dilated pupils are seen in the right (A) and left (B) eyes 
The pathogenesis of ocular complications in dengue fever is not fully understood. Thrombocytopenia in severe dengue may predispose towards hemorrhage. However, clinical presentation and behavior of these complications can suggest an immunogenic etiology rather than an infective one ${ }^{(15)}$. Other postulates include viral mutations, viral virulence and host susceptibility. Viral genetic mutations have been demonstrated to occur within the various serotypes, however the biologic effects induced by these mutations are as yet uncharacterized $^{(15-16)}$. More research is still needed to evaluate the pathogenesis of these ocular manifestations.

Bistis (1929, apud Richardson ${ }^{(17)}$ ) published an article in 1929 concerning the epidemic of dengue in Athens, in which he said that iritis, glaucoma, and retrobulbar neuritis had been mentioned as complications. During the same epidemic Anargyros (1929, apud Richardson ${ }^{(17)}$ ) reported five cases with ocular complications. In one, glaucoma of the left eye appeared on the fourth and last day of the fever, simultaneously with the appearance of the exanthem, and two days later there was a less severe attack of glaucoma in the right eye. Iridectomy was done, first in the left, then in the right eye. Another patient, aged fifty-four years, had two years previously lost the sight of the right eye from glaucoma. The eye had remained painless until convalescence from dengue took place, when the conjunctiva became injected and there was intense pain. The eye was enucleated and the vitreous body was found to be full of blood clots.

Gabrielides (1929, apud Richardson ${ }^{(17)}$ ) observed two cases of angle closure glaucoma during dengue infection in women aged sixty and fifty-four years respectively. In the first case symptoms appeared on the third day; in the second case the symptoms, with the complete loss of vision, appeared on the fourth day. Notwithstanding intensive treatment, the glaucomatous phenomena, and especially the pupillary dilatation, persisted.

Bilateral simultaneous acute angle closure is a rare entity, infrequently reported after psychotropic drug intake ${ }^{(18)}$, general anesthesia ${ }^{(19)}$, or snake bite ${ }^{(20)}$. To the best of our knowledge, no cases of bilateral simultaneous acute angle closure glaucoma related to dengue fever have been reported before.

Our patient presented with bilateral sudden loss of vision, elevated IOP, shallow anterior chamber, corneal edema, and dilated pupils during a febrile illness. The diagnosis of dengue fever was suspected based on leuko- and thrombocytopenia, elevated serum transaminase levels plus dehydration, and this diagnosis was confirmed by serological tests. Longer followup will be required to determine whether this functional visual loss is permanent.

Acute angle closure glaucoma is a potentially blinding side effect of a number of local and systemic drugs, including adrenergic, both anticholinergic and cholinergic, antidepressant and antianxiety, sulfa-based, and anticoagulant agents ${ }^{(21)}$. Although we had not identified the use of these substances by the patient, increased vigilance in such patients treated with these drugs may reduce the risk of this adverse effect.
In conclusion, although dengue fever is considered to be rarely associated with ocular manifestations, with increasing epidemicity and co-circulation of multiple dengue serotypes, the occurrence of DF and DHF is set to rise. Similarly we expect to see an increase in this newly emergent facet of dengue ophthalmic morbidity. A heightened awareness of denguerelated ophthalmic complications among clinicians involved in the care of patients with dengue would facilitate prompt referral for ophthalmologic assessment and management. In addition, bilateral acute angle closed glaucoma is a severe complication that may occur in individuals at risk for angle closure glaucoma with DF. Patients with periorbital pain and visual symptoms should be examined for angle closure glaucoma attack in both eyes.

\section{RESUMO}

Complicações oculares são incomuns na dengue, mas podem resultar em perda visual. Os autores relatam o primeiro caso de um paciente com dengue que apresentou glaucoma agudo bilateral. Testes sorológicos confirmaram a doença. Apesar do tratamento, houve perda visual grave.

Descritores: Dengue/complicações; Glaucoma; Pressão intraocular/etiology; Brasil; Relatos de casos [Tipo de publicação]

\section{REFERENCES}

1. Lim WK, Mathur R, Koh A, Yeoh R, Chee SP. Ocular manifestations of dengue fever. Ophthalmology. 2004;111(11):2057-64.

2. Guzmán MG, Kourí G. Dengue: an update. Lancet Infect Dis. 2002;2(1):33-42. Comment in: Lancet Infect Dis. 2002;2(4):207-8.

3. Wilder-Smith A, Schwartz E. Dengue in travelers. N Engl J Med. 2005; 353(9):924-32. Comment in: N Engl J Med. 2005;353(23):2511-3; author reply 2511-3. N Engl J Med. 2005;353(23):2511-3; author reply 2511-3. N Engl J Med. 2005;353(23):2511-3; author reply 2511-3.

4. Silveira AC. Dengue: aspectos epidemiológicos e de controle. Rev Soc Bras Med Trop. 1998;31(Supl)2:5-14.

5. Secretaria da Saúde do Estado do Ceará. Coordenadoria de Promoção e Proteção à Saúde. Núcleo de Vigilância Epidemiológica. Dengue no Ceará [Internet]. Informe Semanal Dengue. 2007. [citado 2007 Mai 6]; Disponível em http:// www.saude.ce.gov.br/internet/publicacoes/boletins/dengue/dengue_04_05_2007.pdf

6. Rigau-Pérez JG, Clark GG, Gubler DJ, Reiter P, Sanders EJ, Vorndam AV. Dengue and dengue haemorrhagic fever. Lancet. 1998;352(9132):971-7. Comment in: Lancet. 1998;352(9141):1712. Comment on: Lancet. 1999; 353(9158):1100-1.

7. World Health Organization. Dengue haemorrhagic fever: diagnosis, treatment, prevention and control. $2^{\text {nd }}$ ed. Geneva: World Health Organization; 1997.

8. Spitznas M. [Macular haemorrhage in dengue fever (author's transl)]. Klin Monatsbl Augenheilkd. 1978;172(1):105-7. German.

9. Nainiwal S, Garg SP, Prakash G, Nainiwal N. Bilateral vitreous haemorrhage associated with dengue fever. Eye. 2005;19(9):1012-3.

10. Haritoglou C, Dotse SD, Rudolph G, Stephan CM, Thurau SR, Klauss V. A tourist with dengue fever and visual loss. Lancet. 2002;360(9339):1070. Comment in: Lancet. 2003;361(9352):181-2.

11. Siqueira RC, Vitral NP, Campos WR, Oréfice F, de Moraes Figueiredo LT. Ocular manifestations in dengue fever. Ocul Immunol Inflamm. 2004; 12(4):323-7.

12. Cruz-Villegas V, Berrocal AM, Davis JL. Bilateral choroidal effusions associated with dengue fever. Retina. 2003;23(4):576-8.

13. Bacsal KE, Chee SP, Cheng CL, Flores JV. Dengue-associated maculopathy. Arch Ophthalmol. 2007;125(4):501-10. 
14. Kapoor HK, Bhai S, John M, Xavier J. Ocular manifestations of dengue fever in an East Indian epidemic. Can J Ophthalmol. 2006;41(6):741-6. Comment in: Can J Ophthalmol. 2007;42(5):755; author reply 755-6.

15. Chang PE, Cheng CL, Asok K, Fong KY, Chee SP, Tan CK. Visual disturbances in dengue fever: an answer at last? Singapore Med J. 2007;48(3):71-3.

16. Lei HY, Yeh TM, Liu HS, Lin YS, Chen SH, Liu CC. Immunopathogenesis of dengue virus infection. J Biomed Sci. 2001;8(5):377-88.

17. Richardson S. Ocular Symptoms and Complications Observed in Dengue. Trans Am Ophthalmol Soc. 1933;31:450-77.
18. Stangler F, Prietsch RF, Fortes Filho JB. Glaucoma agudo bilateral em paciente jovem secundário ao uso de topiramato: relato de caso. Arq Bras Oftalmol. 2007;70(1):133-6.

19. Ates H, Kayikçioglu O, Andaç K. Bilateral angle closure glaucoma following general anesthesia. Int Ophthalmol. 1999;23(3):129-30.

20. Srinivasan R, Kaliaperumal S, Dutta TK. Bilateral angle closure glaucoma following snake bite. J Assoc Physicians India. 2005;53:46-8.

21. Lachkar Y, Bouassida W. Drug-induced acute angle closure glaucoma. Curr Opin Ophthalmol. 2007;18(2):129-33. 